\title{
Differentiation of Marrow Stromal Cells into Photoreceptors in the Rat Eye
}

\author{
Anthony Kicic, ${ }^{1}$ Wei-Yong Shen, ${ }^{2}$ Ann S. Wilson, ${ }^{3}$ Ian J. Constable, ${ }^{2}$ Terry Robertson, ${ }^{4}$ and P. Elizabeth Rakoczy ${ }^{2}$ \\ ${ }^{1}$ Stem Cell Unit, Department of Molecular Ophthalmology, Lions Eye Institute, affiliated with the Center of Ophthalmology and Visual Science, University of \\ Western Australia, Nedlands, 6009, Western Australia, Australia, ${ }^{2}$ Center of Ophthalmology and Visual Science, University of Western Australia, Nedlands, \\ 6009, Western Australia, Australia, ${ }^{3}$ Department of Molecular Ophthalmology, Lions Eye Institute, affiliated with the Center of Ophthalmology and Visual \\ Science, University of Western Australia, Nedlands, 6009, Western Australia, Australia, and ${ }^{4}$ Department of Pathology, The University of Western \\ Australia, Nedlands, 6009, Western Australia, Australia
}

Retinal degenerations and dystrophies are the major causes of genetically inherited blindness that are characterized by the apoptotic death of the photoreceptor cell layer of the retina. To date, no treatment exists for these diseases and only recently have they been considered as candidates for gene and stem cell therapies. Here we report the ability of adult CD90 ${ }^{+}$marrow stromal cells (MSCs) to be induced by activin A, taurine, and EGF into cells (20-32\%) expressing photoreceptor-specific markers rhodopsin, opsin, and recoverin in vitro. $\mathrm{CD}^{+}{ }^{+}$cells were either transduced with recombinant adeno-associated virus expressing green fluorescent protein (GFP) or bromodeoxyuridine (BrdU) labeled and then injected into the subretinal space of adult Royal College of Surgeons rats. Fundus photography and angiography showed no adverse effects of $\mathrm{CD} 90^{+} \mathrm{MSC}$ transplantation. GFP-expressing cells or BrdU-positive cells covered $\sim 30 \%$ of the entire retinal area. By 2 weeks after injection, $\mathrm{CD} 90^{+} \mathrm{MSC}$ integrated into the host retina, forming structures similar to the photoreceptor layer and expressed a photoreceptor-specific marker. No teratoma formation was observed in the recipient retina. The subretinally delivered $\mathrm{CD}{ }^{+}$MSCs did not stain for proliferating cell nuclear antigen, indicating that they primarily undergo differentiation rather than proliferation. In addition, we established that transplanted cells can attract synaptic vesicles and hence are potentially capable of signal transduction. This study demonstrates for the first time the partial differentiation of adult CD90 ${ }^{+}$MSCs into photoreceptors in vitro and in vivo. Our results establish a proof of concept for $\mathrm{CD}^{+}{ }^{+} \mathrm{MSC}$ differentiation with autologous transplantation, which may provide a promising therapeutic strategy for the treatment of some forms of genetically inherited retinal degenerations.

Key words: marrow stromal cells; photoreceptors; retinal degeneration; stem cells; cell-based therapy; plasticity

\section{Introduction}

Retinal degenerations and dystrophies are the major causes of genetically inherited blindness in the developed world. These conditions are typically characterized by the apoptotic death of one of a subset of cells in the retina, namely the photoreceptors (Gavrieli et al., 1992; Lolley et al., 1994). Because visually evoked responses have been recorded in animals suffering degeneration after photoreceptor transplantation (Huang et al., 1998; Woch et al., 2001), suggesting that despite the partial or complete loss of photoreceptors, function may be maintained in the inner nuclear layer and the axons connecting the retina to the brain. Hence, photoreceptor replacement in the form of a cell-based therapeutic approach might possibly aid in the restoration of some degree of vision. Embryonic stem cell therapy, although promising, remains highly controversial and must overcome the potential problem of rejection. In this respect, if an accessible pluripotent

Received Aug. 26, 2002; revised June 23, 2003; accepted June 24, 2003.

We thank Prof. Miranda Grounds for inspirational discussions. We sincerely thank Dr. Matthew Wikstrom, Christine Hall, Tammy Zaknich, Dr. Meliha Brankov, and Ben Rae for their technical assistance. We also thank Dr. Elizabeth Kicic-Starcevich for her valuable constructive comments.

Correspondence should be addressed to Dr. Anthony Kicic, Stem Cell Unit, Department of Molecular Ophthalmology, Lions Eye Institute, affiliated with the Center of Ophthalmology and Visual Science, University of Western Australia, 2 Verdun Street, Nedlands, 6009, Western Australia, Australia. E-mail: akici@eye.uwa.edu.au. Copyright $\odot 2003$ Society for Neuroscience $\quad$ 0270-6474/03/237742-08\$15.00/0 stem cell source can be identified, autologous stem cell therapies offer a great advantage.

A limited number of retinal stem cells have been successfully extracted from the pigment ciliary margin (Tropepe et al., 2000) and differentiated into neurons, such as photoreceptors, in vitro. Extraction of these cells involves complicated microsurgical procedures, and the limited availability of pluripotent retinal stem cells means that this approach is not an option for the treatment of genetically inherited ocular diseases. In contrast, the bone marrow is an ideal source of pluripotent stem cells, because it is the primary site of hematopoietic stem cell renewal and differentiation. It is comprised of at least two types of stem cells: hematopoietic stem cells and stem cells for nonhematopoietic tissues, which commonly referred to as marrow stromal cells (MSCs). These highly undifferentiated, self-renewing elements were originally thought to be severely limited in their capacity for differentiation, but recent reports of their differentiation into muscle, glial, hepatic, renal, and neural lineages has challenged this notion (Eglitis and Mezey, 1997; Ferrari et al., 1998; Petersen et al., 1999; Kopen et al., 1999). Because of its autologous characteristic, relative ease of isolation, and its less controversial nature, this pool of pluripotent stem cells remains a forerunner as the cells of choice in the treatment of diseases using cell-based therapy.

A number of investigations have shown the multilineage po- 
tential of MSCs into neural lineages (Azizi et al., 1998; Brazelton et al., 2000; Mezey et al., 2000), which prompted us to attempt their induction into photoreceptors in vitro and in vivo. For the first time, we show the ability of adult CD90 ${ }^{+}$MSCs to be induced into cells expressing photoreceptor-specific markers in vitro using activin $\mathrm{A}$, taurine, and epidermal growth factor (EGF). In addition, and more significantly, we demonstrate the successful transplantation of adult $\mathrm{CD} 90^{+}$MSCs into the adult rat eye with minimal side effects, the in vivo survival of these cells, their partial integration and differentiation into the host retina, and potential functional activity.

\section{Materials and Methods}

Reagents. $\alpha$ minimal essential medium ( $\alpha \mathrm{MEM})$, fetal bovine serum (FBS), normal rabbit serum, penicillin G, streptomycin sulfate, trypsinEDTA, L-glutamine, transforming growth factor $\beta 1$ (TGF $\beta 1$ ), murine natural EGF, and TRIzol reagent were purchased from Invitrogen (Melbourne, Australia). Insulin, 5,8,11,14-eicosatetraynoic acid, dexamethasone, bovine serum albumin (BSA), activin A, and taurine were obtained from Sigma (St Louis, MO). PharMingen (San Diego, CA) supplied all primary antibodies and the streptavidin-allophycocyanin conjugate (Sav-APC), with the exception of anti-opsin and anti-collagen type II and all secondary antibodies mentioned, which were obtained from Sigma. The recoverin antibody was purchased from ProteinTech Group (Chicago, IL). Triton X-100 was supplied by BDH Chemicals (Victoria, Australia). All tissue culture plasticware was obtained from Becton Dickinson (Franklin Lakes, NJ).

Isolation and culture of MSCs. The primary culture of rat MSCs was performed using standard techniques described previously (Phinney et al., 1999; Woodbury et al., 2000), in accordance with the policy of The Society of Neuroscience for animal use in experimentation.

Stromal cell characterization and purification. The CD $90^{+}$MSCs were analyzed using fluorescent-activated cell sorting (FACS) (FACSCalibur; Becton Dickinson). In brief, harvested cells were fixed with $70 \%$ methanol, washed in PBS, and incubated for $1 \mathrm{hr}$ on ice with fluorescentconjugated monoclonal antibodies (1:100 dilution) directed against the following cell surface markers: CD11b, CD45, and CD90. After washing, secondary antibody (SAv-APC; 1:100 dilution) was added, and the cells were incubated on ice for $1 \mathrm{hr}$. Cells were washed an additional two times before analysis. For purification, the cells were sorted using a FACSVantage cell sorter (Becton Dickinson) after the fluorescence-labeling procedure mentioned above, with the exception that the cells were not fixed before analysis. MSCs solely expressing CD90 were then aseptically collected, recultured, and used in all subsequent experiments.

Multipotency of $\mathrm{CD}^{+} \mathrm{O}^{+} \mathrm{MSCs}$. Adipogenic differentiation was performed using a method described previously (Kopen et al., 1999), and the cells were stained with Oil Red O and Sudan Black B. Chondrogenic differentiation was performed using a modified method of Muraglia et al. (2000), in which CD90 ${ }^{+}$cells were cultured in $\alpha$ MEM and TGF $\beta 1$ (10 $\mathrm{ng} / \mathrm{ml}$ ) for $8-10 \mathrm{~d}$. Cells were then fixed and stained for type II collagen expression.

Photoreceptor induction in vitro. After $24 \mathrm{hr}$ in culture, basal medium for $\mathrm{CD} 90^{+}$cells was replaced with $\alpha$ MEM supplemented with FBS $(1 \%$ $\mathrm{v} / \mathrm{v})$, penicillin $(100 \mathrm{U} / \mathrm{ml})$, streptomycin $(100 \mu \mathrm{g} / \mathrm{ml})$, and one of the following inducing agents: activin $\mathrm{A}(100 \mathrm{ng} / \mathrm{ml})$, taurine $(50 \mu \mathrm{M})$, or EGF $(100 \mathrm{ng} / \mathrm{ml})$. Cells were cultured for an additional $8-10 \mathrm{~d}$, fixed, and then immunocytochemically analyzed.

Immunocytochemistry. CD90 ${ }^{+}$MSCs were fixed, washed, and then blocked in $5 \%(\mathrm{w} / \mathrm{v})$ BSA, $10 \%$ FBS $(\mathrm{v} / \mathrm{v})$, and $0.1 \%(\mathrm{v} / \mathrm{v})$ Triton X-100 in $1 \times$ PBS for $1 \mathrm{hr}$ at room temperature. Cells were incubated with various primary antibodies for $24 \mathrm{hr}$ at $4^{\circ} \mathrm{C}$ followed by secondary antibodies (FITC-tetramethylrhodamine isothiocyanate-conjugated or Streptavidin biotin) for a similar period. The antibody complex was visualized using a fluorescent microscope (Olympus Optical, Tokyo, Japan). Primary antibodies included the following: microtubule-associated protein 2 (MAP2; 1:500), glial fibrillary acid protein (GFAP; 1:500), rhodopsin (RHOS; 1:100), protein kinase C (PKC; 1:100), cellular retinoic acidbinding protein-1 (CRABP1; 1:100), and nestin (1:1000).
Western blot analysis. CD90 ${ }^{+}$MSCs incubated with each inducing agent over a $10 \mathrm{~d}$ period were collected and lysed, and $\sim 40 \mu \mathrm{g}$ of cellular protein as well as rat retinal tissue (positive control) was electrophoresed on a $12 \%(\mathrm{w} / \mathrm{v})$ SDS-polyacrylamide gel. Separated proteins were transferred electropheretically onto a nitrocellulose membrane $(100 \mathrm{~mA} ; 1 \mathrm{hr}$; $4^{\circ} \mathrm{C}$ ) and immunoblotted using photoreceptor-specific antibodies. In brief, membranes were blocked for $1 \mathrm{hr}$ at room temperature with 5\% $(\mathrm{w} / \mathrm{v})$ skim milk powder in PBS and $0.05 \%(\mathrm{v} / \mathrm{v})$ Tween 20 . After washing, membranes were incubated at room temperature with primary antibodies [recoverin, 1:100 diluted in 5\% (w/v) skim milk powder in PBS; opsin, 1:500 diluted in PBS] for $1 \mathrm{hr}$ and then washed three times at 10 min intervals. The membranes were then incubated with 1:20,000 dilution of the secondary anti-rabbit IgG and anti-mouse IgG horseradish peroxidase-linked antibodies for recoverin and opsin, respectively, for 1 $\mathrm{hr}$ at room temperature and then washed for another $30 \mathrm{~min}$. Opsin and recoverin expression was then visualized using the ECL and ECL Plus Western blotting detection systems, respectively (Amersham Biosciences, Buckinghamshire, UK).

Semiquantitative reverse transcriptase PCR of the genes for differentiation markers of multilineages. Total RNA was extracted from the cells using TRIzol reagent and was enriched for mRNA using the RNeasy mini columns (Qiagen, Hilden, Germany) following the instructions of the manufacturer. Primers were designed for the following genes: glyceraldehydes-3-phosphate dehydrogenase (GAPD) (GenBank accession number AF106860) 5' (301-321), 3' (561-542); PCNA ( proliferating cell nuclear antigen) (GenBank accession number NM 022381) 5' (163182), 3'(1116-1094); recoverin (GenBank accession number D12573) 5'(429-449), 3'(1440-1420); peripherin (GenBank accession number AF031878) 5'(671-691), 3'(1540-1520); opsin (GenBank accession number U22180) 5'(73-93), 3'(504-485); lipoprotein lipase (GenBank accession number L03294) 5'(2811-2831), 3'(3468-3448); and collagen type II (GenBank accession number L48440) 5'(3509-3527), 3' (39823962). The cDNA was synthesized and amplified using the OneStep reverse transcriptase (RT)-PCR kit (Qiagen) under the following conditions: reverse transcription at $50^{\circ} \mathrm{C}$ for $30 \mathrm{~min}$, initial PCR activation at $95^{\circ} \mathrm{C}$ for $15 \mathrm{~min}$ followed by 35 cycles of denaturation at $94^{\circ} \mathrm{C}$ for $1 \mathrm{~min}$, annealing at $56-62^{\circ} \mathrm{C}$ for $1 \mathrm{~min}$, and extension at $72^{\circ} \mathrm{C}$ for $1 \mathrm{~min}$. A final extension step at $72^{\circ} \mathrm{C}$ for $10 \mathrm{~min}$ was included before samples were being cooled to $4^{\circ} \mathrm{C}$. The RT-PCR samples were then separated by $1.6 \%$ agarose gel electrophoresis and photographed.

In vivo transplantation of CD $90^{+}$MSCs. A total of 28 Royal College of Surgeons (RCS) rats were subretinally injected with stem cells using a modified method of Shen and Rakoczy (2001). Between 50 and 100,000 $\mathrm{CD} 90^{+}$MSCs prelabeled with either bromodeoxyuridine (BrdU; $5 \mu \mathrm{M}$ ) or recombinant adeno-associated virus expressing green fluorescent protein (rAAV.GFP) in $2 \mu \mathrm{l}$ of PBS were injected into the left eye while the other eye (control) was injected with $2 \mu$ l of PBS. Eyes were monitored up to 12 weeks after transplantation by fundus color photography and angiography. Enucleated eyes were then frozen in optimal cutting temperature compound, sectioned, and then stained for BrdU (1:50), rhodopsin (1:100), synaptophysin (1:200), and PCNA (1:250) using the methods described above. Control sections were counterstained to observe nuclei. For electron microscopic examination, animals were killed under halothane anesthetic and eyes were carefully removed and placed into a fixative solution containing $4 \%$ paraformaldehyde and $0.5 \%$ glutaraldehyde in $0.05 \mathrm{~m}$ cacodylate buffer, $\mathrm{pH}$ 7.4. The eyes were then trimmed and reimmersed into a fresh solution of the same fixative for an additional 24 hr. After postfixing in $1 \%$ osmium tetroxide, the tissues were then processed for transmission electron microscopy (TEM) by conventional methods and embedded in Araldite. Semithin sections ( $1 \mu \mathrm{m}$ thick) were stained with $0.5 \%$ toluidine blue in $5 \%$ borax and examined with a Zeiss (Thornwood, NY) light microscope. Immunohistochemical analysis using BrdU was used to identify transplanted cells. Staining revealed that a majority of transplanted cells was found at the injection site or at the proximal end of the outer nuclear layer (ON) (data not shown). These sections, in which transplanted cells predominated, were then carefully trimmed under a dissecting microscope, and thin sections (70nm thick) were prepared using an LKB-Wallac (Gaithersburg, MD) Nova ultramicrotome. The sections were stained with Reynold's lead citrate and ex- 

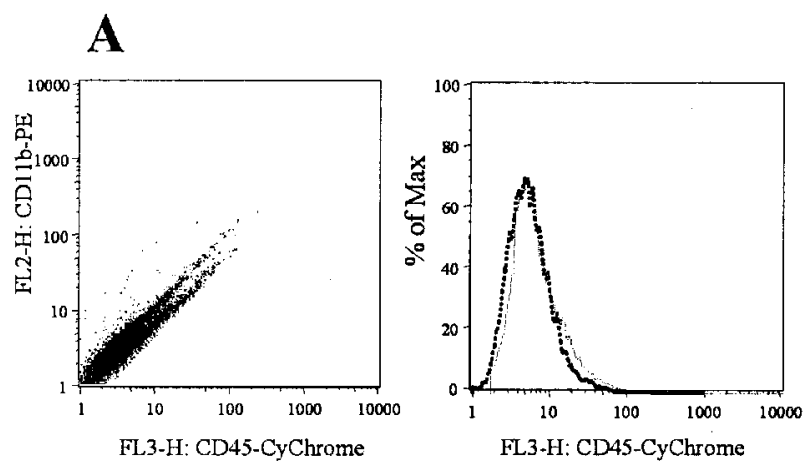

B
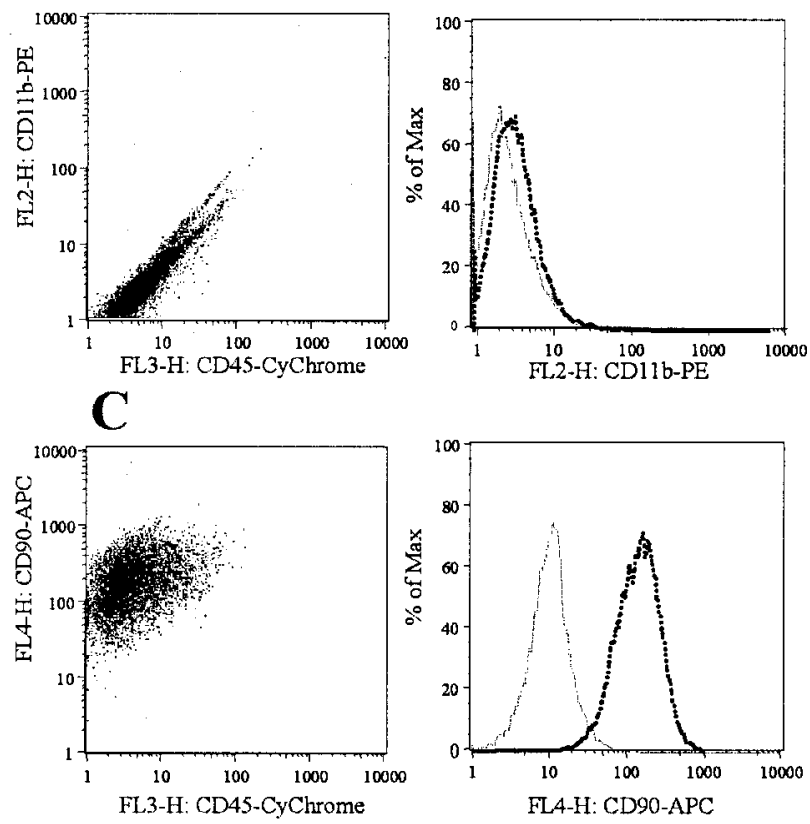

Figure 1. $\quad A-C$, Forward and side scatter plots of CD45 (A), CD11b (B), and CD90 ( $C$ cells showing the characterization of undifferentiated rat MSCS. Population profiles of first-passage MSCs were found to primarily express CD90 (84 $\pm 3.8 \%)$.

amined in a Philips (Einhoven, The Netherlands) 410LS TEM at an accelerating voltage of $80 \mathrm{kV}$.

Transduction of CD90 ${ }^{+}$MSCs. CD90 ${ }^{+}$MSCs were transduced with an rAAV.GFP in $\alpha$ MEM using the method of Lai et al. (2001).

\section{Results}

\section{Stromal cell characterization}

With the aim of producing a more unified cell population, primary cultures of MSCs obtained from normal adult RCS$\mathrm{rdy}^{+}-\mathrm{p}^{+}$rats were passaged once before analysis by fluorescent flow cytometry. We analyzed three individually prepared samples of MSCs and found all cells to be negative for CD45, the cell surface marker for the leukocyte cell lineage (Fig. $1 \mathrm{~A}$, Table 1). In addition, a small proportion of the population $(2.4-5.8 \%)$ was found to express CD11b, the standard cell surface marker for the erythrocyte lineage (Fig. $1 B$, Table 1 ). In contrast, $\sim 84 \%$ of firstpassage MSCs expressed CD90 (Fig. 1C, Table 1), the undifferentiated cell marker. This population profile changed markedly with continual passage (Table 1 ). MSCs of early passage primarily expressed CD90 ( $>80 \%)$, which decreased with subsequent passages to $<20 \%$ (Table 1 ). However, a statistically significant decrease $(p<0.001)$ in the number of $\mathrm{CD} 90^{+}$cells only occurred
Table 1. The effect of passage on MSC differentiation

\begin{tabular}{lllr}
\hline Passage number & CD45 (\%) & CD11b (\%) & \multicolumn{1}{c}{ CD90 (\%) } \\
\hline 1 & - & $4.15 \pm 1.7$ & $84 \pm 3.8$ \\
4 & - & $2.11 \pm 0.83$ & $80.3 \pm 4.4$ \\
8 & - & $1.98 \pm 0.57$ & $68.92 \pm 6.1$ \\
12 & - & $1.25 \pm 0.24$ & $66.45 \pm 7.8$ \\
15 & - & $0.61 \pm 0.02$ & $41.75 \pm 6.2$ \\
20 & - & $0.83 \pm 0.2$ & $42.22 \pm 5.9$ \\
23 & - & $0.1 \pm 0.01$ & $17.5 \pm 5.5$ \\
\hline
\end{tabular}

The percentage of MSCs expressing CD90 remains constant up to passage four but significantly decreases $(p<$ 0.001 ) by the eighth passage.

after eight passages, indicating that an accessible source of undifferentiated cells exists in early passage MSCs.

\section{In vitro photoreceptor differentiation}

The plasticity of $\mathrm{CD} 90^{+}$MSCs was confirmed by initiating their differentiation into adipogenic and chondrogenic cell lineages. This was confirmed by RT-PCR, demonstrating the expressions of lipopolylipase and type II collagen, respectively (data not shown).

The potential of $\mathrm{CD} 90^{+} \mathrm{MSC}$ s to differentiate into any of the retinal cell lineages was assessed by exposing them to the following specific inducing agents: taurine, activin $\mathrm{A}$, and EGF. After induction with taurine, activin A, and EGF, $\sim 30 \%$ of the cell population expressed RHOS, a photoreceptor-specific cell marker (Figs. $2 B--D$, $3 A$ ). Similarly, $30 \%$ of the $\mathrm{CD} 90^{+}$MSCs stained positively for CRABP1, an amacrine cell marker (Figs. $2 G--I, 3 A)$. All three agents also induced a small number of $\mathrm{CD} 90^{+}$MSCs $(\sim 6-10 \%)$ to express nestin, a typical neural stem cell marker (Figs. $2 L--N, 3 A$ ). Untreated control CD $90^{+}$MSCs did not stain against any of the markers tested (Fig. $2 E, J, O$ ). In addition, none of the treated MSCs showed positive staining with the monoclonal antibody to PKC, which specifically identifies bipolar cells in the retina, astrocytic marker GFAP, or MAP2, a neural cell marker (data not shown).

Photoreceptor-specific differentiation was also confirmed using Western blot analysis and RT-PCR. Incubation of CD $90^{+}$ MSCs with activin A, taurine, or EGF (Fig. $3 B$, lanes 3-5, $C, D$, lanes $2-4$, respectively) all resulted in the expression of the photoreceptor-specific encoders opsin (Fig. $3 B, C$ ) and recoverin (Fig. $3 \mathrm{~B}, \mathrm{D}$ ). Undifferentiated control $\mathrm{CD} 90^{+} \mathrm{MSC}$ incubated in a basal medium did not express any of these markers (Fig. $3 B$, lane 2, $C, D$, lane 5). $\mathrm{CD} 90^{+}$MSCs incubated in the same inducing agents (Fig. 3E, lanes 6-8) as well as undifferentiated controls (Fig. 3E, lane 9) were all found to express the proliferation marker PCNA. Equal loading of samples was confirmed by the expression of GAPD (Fig. 3E, lanes 2-5).

\section{In vivo photoreceptor differentiation}

Having established that $\mathrm{CD} 90^{+}$MSCs could be driven to express photoreceptor lineage-specific markers in vitro, we examined the influence of the ocular microenvironment on the fate of these cells. Subretinal injection of both PBS and a single-cell suspension of uninduced $\mathrm{CD} 90^{+}$MSCs into 4-5-week-old recipient animals resulted in the formation of a subretinal bleb covering approximately one-third of the entire retina (Fig. $4 A, B$ ). The injected subretinal fluid was almost entirely absorbed by day 4 after injection (data not shown). Color fundus photography between 1 and 5 weeks after injection revealed no teratoma formation in the recipient retina (Fig. 4C,E). Immunohistochemical analysis also confirmed the nonproliferating nature of transplanted CD $90^{+}$MSCs by the lack of staining for the cell prolif- 

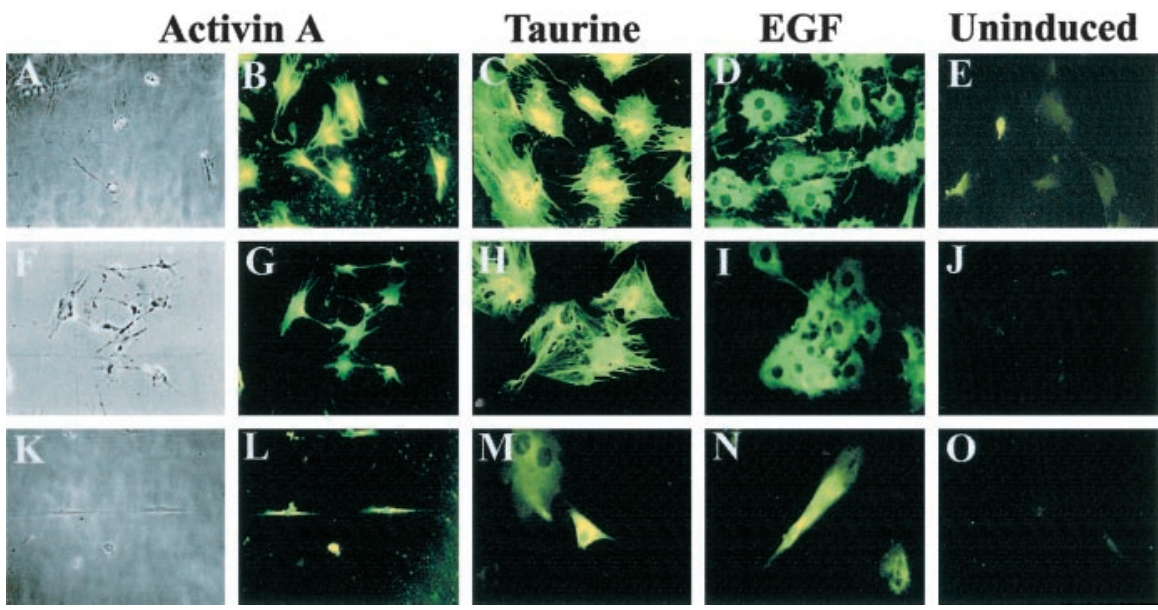

Figure 2. $A, F, K$, Phase contrast micrographs of $\mathrm{CD} 0^{+} \mathrm{MSC}$ induced by activin A. Fluorescent micrographs of immunocytochemical analysis of $C D 90^{+} \mathrm{MSC}$ induced by activin $\mathrm{A}(B, G, L)$, taurine $(C, H, M)$, and $\mathrm{EGF}(D, I, N)$, using photoreceptor (RHOS) $(B-E)$, amacrine (CRABP1) $(G-J)$, and neural (nestin) $(L-O)$ specific antibodies, are shown. Uninduced $C D 90^{+} M S C s$ cells did not stain for any markers tested $(E, J, 0)$. Magnification, $400 \times$
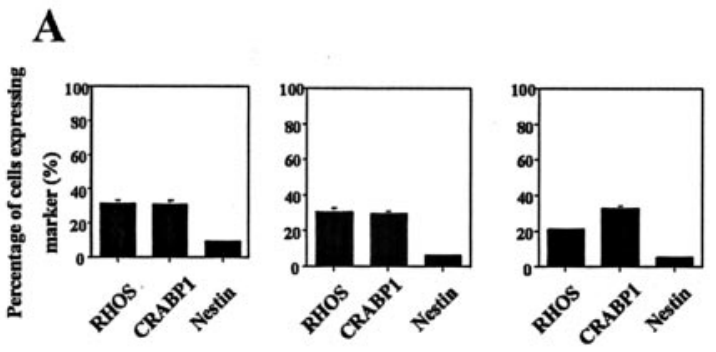

B

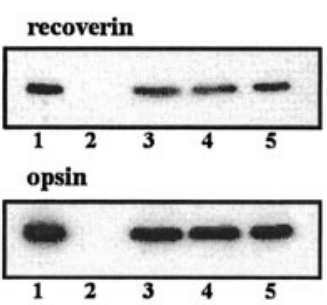

D

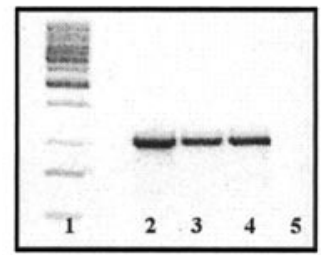

C

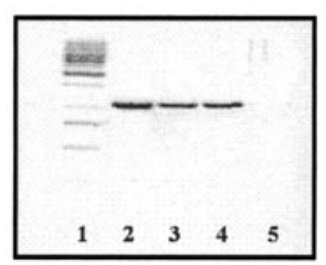

$\mathbf{E}$

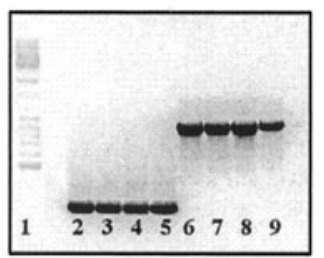

Figure 3. A, Quantification of $\mathrm{CD} 90^{+}$cell differentiation after induction with activin $\mathrm{A}$ taurine or EGF using RHOS (photoreceptor), CRABP1 (amacrine), and nestin (neural)-specific markers, respectively. $B$, Western blot analysis of induced $C D 90^{+}$MSCs. Note that rat retinal tissue (lane 1), undifferentiated CD90 ${ }^{+}$MSCS (lane 2), activin A (lane 3), taurine (lane 4), and EGF (lane 5) are shown. C, D, RT-PCR of opsin ( $C$ and recoverin ( $D)$. Note that, in $C-E$, activin $A$ (lanes 2, 6), taurine (lanes 3, 7), EGF (lanes 4, 8), and undifferentiated $\mathrm{CD}^{+} 0^{+}$cells (lanes 5, 9) are shown. $C, D$, Undifferentiated $C D 0^{+}$cells were found to not express any of these markers (lane 5). E, GAPD expression (lanes 2-5) and proliferating marker PCNA expression (lanes 6-9).

eration marker PCNA (data not shown). The delivered MSCs were quite evenly distributed in the injected area, but cell clumps were occasionally observed (Fig. $4 E$, arrows). The injected $\mathrm{CD} 90^{+}$MSCs were unable to migrate outside the perimeter of the photoreceptor outer and inner segment layers and incorporated into the $\mathrm{ON}$ among the nuclei of photoreceptors in the area defined by the bleb (Fig. 5G). The presence of BrdU-labeled cells in the ON was also confirmed at 12 weeks after injection, although signal intensity was weaker (Fig. 5I). There were no BrdU-labeled cells found in areas distant to the injection site (Fig. $5 F, H)$. These results demonstrated that $\mathrm{CD} 90^{+}$MSCs not only integrated into the retina but also remained there for an extended period of time, providing an opportunity for these cells to differentiate into neural retinal cells.

At all time points, the majority of the integrated BrdU-labeled cells was found in the ON (Fig. 5J). Mature photoreceptors have a unique structure comprising of stacks of photoreceptor nuclei forming the outer nuclear layer and an elongated cytoplasm forming the photoreceptor inner and outer segments (Besharse and Pfenninger, 1980). Opsin, the protein forming the visual pigment, is normally present in the photoreceptor inner and outer segments but is not detectable in the outer nuclear layer (Fig. $5 \mathrm{~K}$ ). Eyes injected with $\mathrm{CD} 90^{+}$MSCs show the typical outer segment staining of opsin in undisrupted retinas distant to the injection site (Fig. 5L). However, the vast majority of cells located at the injection site demonstrated typical RHOS antibody staining in their cytoplasm (Fig. $5 \mathrm{M}, \mathrm{N}$ ), which paralleled observations made in vehicle-injected control animals (data not shown). Additional investigation demonstrated that a number of the cells that were immunoreactive for the RHOS antibody within their cytoplasm were also positive for BrdU (Fig. 5O, bottom arrows) and could be distinguished easily from endogenous photoreceptors, the opsin expression of which had been translocated to their cytoplasm caused by the retinal detachment resulting from the injection procedure (Fig. 5O, top arrow). It was interesting to note that whereas BrdU demonstrated nuclear localization, RHOS staining was cytoplasmic surrounding the green nuclei (Fig. 5O, inset). However, even at 12 weeks after injection, the morphology of the double-labeled cells remained circular, and there were no morphological changes suggesting outer segment development. Considering the localization of these cells in the $\mathrm{ON}$ and that opsin is exclusively expressed by photoreceptors, it is proposed that RHOS immunoreactivity present in the ON demonstrates the presence of immature photoreceptors.

One of the most important prerequisites for the development of 

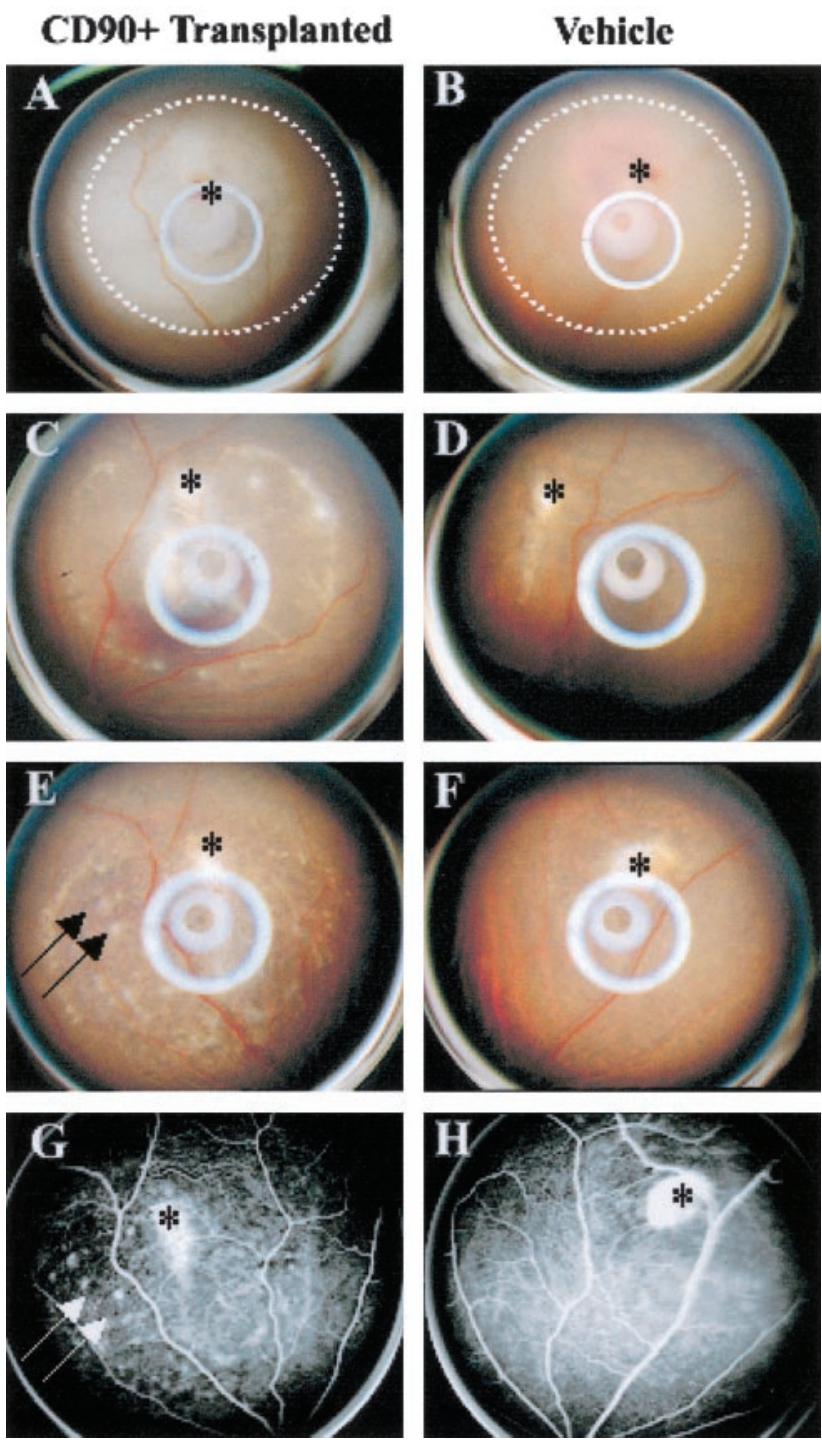

Figure 4. Ophthalmic examination of $\mathrm{CD} 90^{+} \mathrm{MSC}$ transplanted retinas at different time intervals. $A-H$, Fundus photographs $(A-F)$ and fluorescein angiograms $(G, H)$ after subretinal injection of $\mathrm{CD} 90^{+} \mathrm{MSC}$. Subretinal injection induced temporary retinal detachment $(A, B$ circled by dotted lines) with the size of one-third of the whole retina. $C-F$, Distribution of $\mathrm{CD}{ }^{+} \mathrm{MSC}$ at 2 weeks $(C, D)$ and 5 weeks $(E, F)$ after injection. Even distribution with some clumped cells is present (arrows). Note that no teratoma formation was observed up to 5 weeks after injection. $G, H$, Fluorescein angiograms of $\mathrm{CD}^{+} 0^{+} \mathrm{MSCS}(G)$ and vehicle (control) $(H)$ injected eyes at 5 weeks after injection. Note that no sign of ocular neovascularization is present. Asterisks indicate sites of subretinal injection. Solid circles, Artifactual reflex from the modified clinical fundus camera.

a functional photoreceptor layer is the ability of the transplanted cells to establish neuronal connections. Synaptophysin, a synaptic vesicle protein involved in neuronal transmission (Weidmann and Franke, 1985), is typically observed in the outer plexiform and ganglion layers of normal retina (Fig. 5P). Immunohistochemical studies revealed that the BrdU-positive cells in $\mathrm{CD} 0^{+}$MSC-injected eyes colocalized within areas that were immunoreactive for synaptophy$\sin$ (Fig. 5Q). Because a majority of BrdU-labeled cells was observed primarily at the proximal end of the outer nuclear layer by 5 weeks after transplantation (Fig. 5R), closer inspection of these sites via electron microscopy demonstrated the presence of synaptic vesicles surrounding transplanted cells (Fig. 5S).

\section{Transduction of MSCs}

To avoid rejection related to allogeneic transplantation, we propose autologous heterotopic transplantation using the recipients' own MSCs. The genetic abnormality responsible for the development of retinal dystrophy or degeneration will therefore still be present in the MSCs. To investigate the potential of combining gene and stem cell therapies, we used a rAAV.GFP to transduce solely expressing CD90 ${ }^{+}$MSCs. In our hands, $\sim 5-7 \%$ of CD $90^{+}$ MSCs were successfully transduced (Fig. 6A,B). GFP ${ }^{+}$cells were sorted and expanded once for subsequent in vivo experiments. At 3 weeks after injection, examination of whole-mounted retinas transplanted with rAAV.GFP-transduced CD90 ${ }^{+}$MSCs showed the presence of $\mathrm{GFP}^{+}$cells covering approximately one-third of the total retina (Fig. $6 C$ ). The signal intensity decreased with increasing distance from the injection site (Fig. 6D) and finally disappeared beyond the border of the retinal bleb. Histological assessment of the injection site (Fig. $6 E, F$ ) confirmed this finding with a large proportion of $\mathrm{GFP}^{+}$cells located at the site of injection (Fig. 6E, arrows) within the $\mathrm{ON}$ (Fig. 6F, arrows).

\section{Discussion}

Embryonic stem cell therapies may hold enormous potential for the treatment of a wide range of degenerative diseases. However, this approach remains highly controversial, and in many countries, legislation has been introduced to limit their derivation and use (Vogel, 2000). In addition, the problem of rejection still needs to be resolved. This has been highlighted by a recent study by Drukker and colleagues (2002), which has shown that human embryonic stem cell major histocompatibility complex class I expression moderately increases with in vitro and in vivo differentiation, suggesting that these cells may be rejected during transplantation. In this respect, the identification of an easily available stem cell source would offer the advantage of autologous stem cell therapies. Results of recent investigations (Azizi et al., 1998; Brazelton et al., 2000; Mezey et al., 2000) have demonstrated the plasticity of MSCs into neural lineages. This prompted us to attempt their differentiation into photoreceptors for both in vitro, whereby MSCs were exposed to particular agents described previously to induce stem cell differentiation into photoreceptors, and in vivo, whereby MSCs were transplanted into the subretinal space of normal rats, and cell fate was assessed over 3 months.

A number of previous investigations has demonstrated MSC plasticity by their differentiation into chondrogenic, adipogenic, and osteogenic cell lineages (Mackay et al., 1998; Kopen et al., 1999; Pittenger et al., 1999; Muraglia et al., 2000). This multilinear potential has been highlighted also with several recent studies showing successful differentiation of MSCs into muscle, glia, epithelia, and liver cells (Eglitis and Mezey, 1997; Ferrari et al., 1998; Kopen et al., 1999; Petersen et al., 1999; Orlic et al., 2001; Jiang et al., 2002).

Preliminary characterization confirmed previous findings that heterogenous rat MSC populations primarily express CD90 with little or no lymphohematopoietic cell marker expression (Table 1). Analysis also revealed that these cells expressed very low or negligible levels of CD11b and CD45, which are typically expressed by the default cell types for MSCs. Future immunoblotting experiments on those cells that did not express any of the marker tested in this study could then be used to obtain a complete phenotypic profile of MSCs.

A number of previous investigations have demonstrated that taurine, activin A, and EGF are present in the retina and are possibly involved in inducing photoreceptor differentiation both during embryonic development (Lillien and Cepko, 1992; Davis 

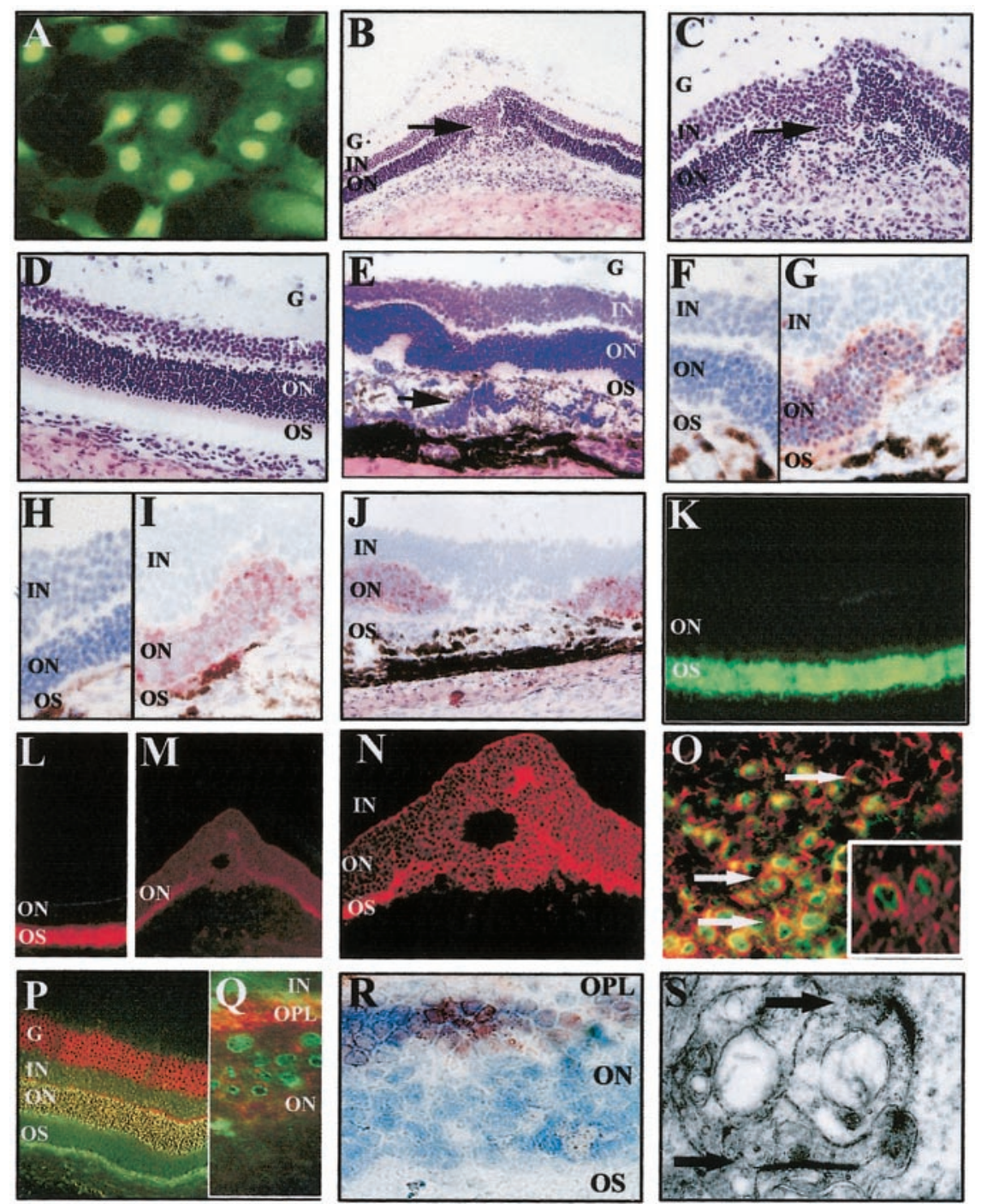

Figure 5. $A-S, C D 90^{+} \mathrm{MSC}$ fate 1-12 weeks after transplantation. $A, C D 90^{+} \mathrm{MSC}$ were prelabeled with BrdU before injection $(400 \times) . B-E, H$, Hematoxylin and eosin $(H, E)$ staining of retinas $7 \mathrm{~d}$ after transplantation $(B-D)$ revealed a large number of $\mathrm{CD90}{ }^{+} \mathrm{MSCs}$ in the subretinal space at the site of injection $(B$, arrow) $(100 \times)$, with only slight disruption to the host retina (C, arrow) $(200 \times)$ occurring at the site of injection. Retina distant to the injection site $(D)(200 \times)$ revealed normal structural integrity. E, Retinas 5 weeks after transplantation histologically appeared normal with very little disruption to the host $(200 \times)$. Pockets of $\mathrm{CD} 90^{+} \mathrm{MSC}$ were observed still in the subretinal space, although these were observed primarily at the site of injection (arrow) (200X). G, I, Detection of BrdU-labeled CD90 ${ }^{+}$MSCs in the 0 N at the site of injection at $7 \mathrm{~d}(\mathrm{G})(300 \times)$ and 5 weeks ( $)$ after transplantation $(300 \times) . F, H$, Retina distant to the injection site appeared normal and did not contain any transplanted cells at $7 \mathrm{~d}(F)(300 \times)$ and 5 weeks $(H)(300 \times)$ after transplantation. Even 5 weeks after transplantation, $\mathrm{CD} 90^{+}$cells were still primarily found within the $\mathrm{ON}(J)$ $(200 \times)$, adjacent to the injection site of host retinas. $K$, Expression of the photoreceptor-specific marker opsin revealed typical outer segment staining in nontransplanted retinas $(300 \times)$. L, A similar pattern of opsin expression in host retina distant to the injection site $(100 \times) . M$, At the injection site, the outer segment staining becomes less apparent, because the structural hierarchy of the host retina is not fully restored after transplantation but is primarily expressed in the cytoplasm of cells located within the injection site $(100 \times) . N$, Higher magnification of the injection site revealed the cytoplasmic expression of opsin in these cells $(400 \times)$. 0 , Transplanted cells were identified by the coexpression of BrdU (green) and opsin (red) within the injection site $(1000 \times$; inset, $2000 \times$ ). Bottom arrows highlight two injected MSCs that were immunoreactive for BrdU and the RHOS antibodies. The top arrow indicates an endogenous photoreceptor whose opsin expression had been translocated to its cytoplasm as a result of the injection procedure. $P$, Synaptophysin expression in nontransplanted retina typically stains positive (indicated as red) in the outer plexiform and ganglion cell layers $(100 \times)$. Q, Higher magnification reveals the colocalization of BrdU and synaptophysin in $C D 90^{+} \mathrm{MSC}-$ transplanted retina $(1000 \times) . R$, Immunohistochemical analysis of transplanted retina revealed that the majority of BrdU-labeled cells was located at the proximal end of the $0 \mathrm{~N}$, adjacent to the OPL (1000X). S, Electron microscopic analysis of these cells revealed synaptic vesicle formation (arrows) (31,200X). G, Ganglioniccell layer; $\mathrm{IN}$, inner nuclear layer; $\mathrm{OPL}$, outer plexiform layer; 0 S outer segments.

et al., 2000) and postnatally (Anchan et al., 1991; Altshuler et al., 1993). It has been observed that embryonically derived retinal precursors require the presence of EGF to sustain their undifferentiated state and that its primary activity is to promote prolifer- ation rather than differentiation in vitro (Ahmad et al., 1998, 1999). However, to our knowledge, this is the first investigation to show that these agents are capable of inducing adult-derived $\mathrm{CD} 90^{+}$MSCs to express photoreceptor-specific markers in vitro. Having demonstrated their differentiation via specific marker expression by Western blot analysis and RT-PCR, additional studies using a more quantitative approach would be required to see whether the specific photoreceptor marker expression patterns observed in this study correlate to the expression patterns of normal functioning photoreceptors.

Previous studies have shown that bone marrow-derived stem cells (Tomita et al., 2002) and neural progenitor cells (Nishida et al., 2000; Young et al., 2000; Pressmar et al., 2001) can integrate and differentiate more readily in diseased retinas than in healthy retinas. One of the major concerns of stem cell or pluripotent cell injection is adverse effects related to uncontrolled cell proliferation. Considering the potential applications, it is an important observation that $\mathrm{CD} 90^{+} \mathrm{MSC}$ can be successfully injected into animals without any serious pathological consequences. Our findings suggest that once in the retinal microenvironment, $\mathrm{CD}{ }^{+}$MSCs either undergo differentiation into potentially functioning photoreceptors or remain undifferentiated with little disruption to the host retinal morphology. Biological complications like that related to neoplasia seem unlikely, because color fundus photography 12 weeks after transplantation (data not shown) showed a similar morphology to that observed at 5 weeks (Fig. 4), and transplanted cells did not show any immunoreactivity to PCNA, a proliferation marker (data not shown). However, in this study, the signal intensity of BrdU-labeled transplanted cells did in fact diminish over time. This observation may suggest that in the case of syngenic transplantations, the long-term survival of transplanted cells in the retina remains uncertain, which could be a cause for concern (Zhang and Bok, 1998). Additional studies are required to investigate this further.

Previously, Chacko et al. (2000) showed that embryonic retinal progenitor cells could be transplanted into the subretinal space of 2-week-old rats, and that at $26 \mathrm{~d}$ after transplantation, injected progenitor cells had incorporated into the host retina and expressed opsin and recoverin without disrupting the morphology and laminar organization of the host retina. Work conducted by Kopen et al. (1999) observed that CD90 ${ }^{+}$MSCs could also be successfully engrafted into the neonatal brain, which results in their differen- 

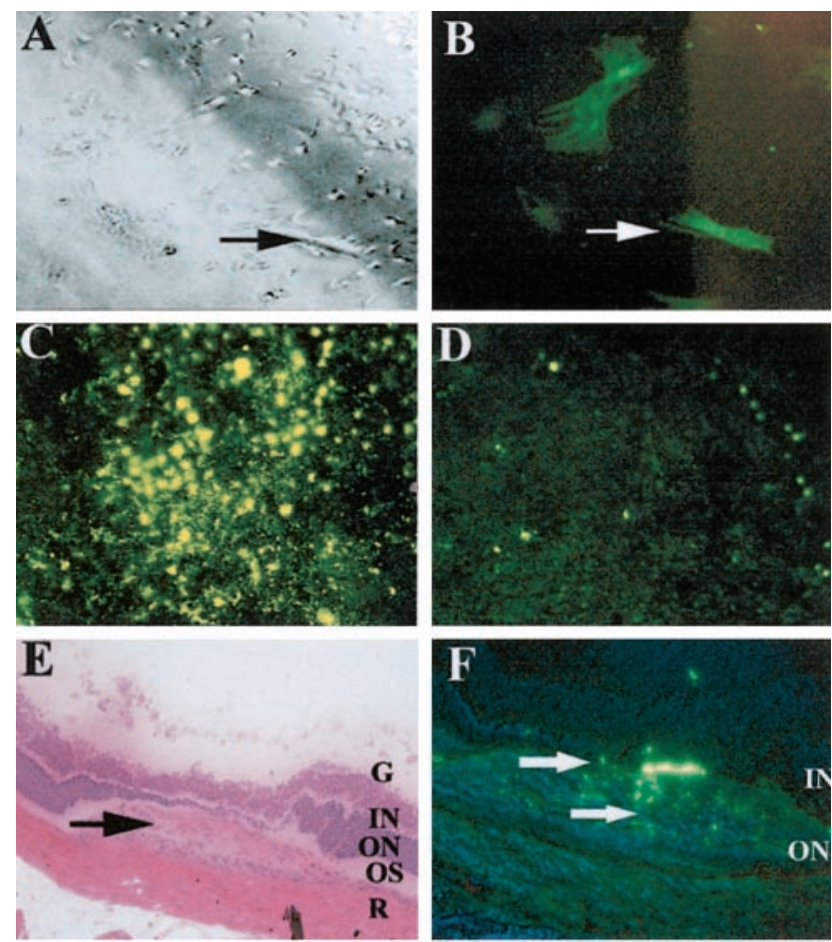

Figure 6. $A, B$, Phase contrast $(A)$ and fluorescent $(B)$ micrographic images of $C D 90^{+} \mathrm{MSCS}$ transduced with rAAV.GFP before transplantation. Fluorescent micrographic images of wholemounted retina at 3 weeks after transplantation of rAAV. Arrows highlight a particular $\mathrm{CD} 90^{+}$ MSC that had been successfully transduced with rAAV-GFP. C, D, GFP-transduced CD $90^{+} \mathrm{MSC}$ adjacent $(C$ and distant $(D)$ to the injection site $(400 \times)$. E, F, Hematoxylin and eosin staining ( $E$; arrow indicates site of injection) and fluorescent microscopy ( $F$; top arrow indicates site of injection and bottom arrow indicates transplated cells located at the site of injection) of transplanted rAAV.GFP transduced CD90 ${ }^{+}$MSCs (200X). G, Ganglionic cell layer; IN, inner nuclear layer; $O S$, outer segments; $R$, retinal pigment epithelium.

tiation into astrocytes and neurons without disrupting the surrounding tissue. These observations demonstrated that photoreceptors could potentially be produced from embryonic retinal progenitor cells, and that engrafting into neuronal tissue does not induce neoplasia. However, the clinical benefits of these observations for the treatment of retinal degenerative disorders are somewhat limited because of ethical issues, limited accessibility, number of retinal progenitor cells, and the potential of tissue rejection by the host.

Our observation that adult $\mathrm{CD} 90^{+}$MSCs injected into the subretinal space of adult rats can be differentiated into photoreceptors with similar efficiency as embryonic retinal progenitor cells offers a potential treatment strategy for retinal degenerations and dystrophies. Our in vivo results also correlate well to the preliminary findings of Tomita and colleagues (2002), who showed similar levels of integration and differentiation of bone marrow-derived stem cells when injected into the intravitreous space of rats whose retinas were mechanically injured. Importantly, we found that adult autologous heterotopic transplantation of $\mathrm{CD} 0^{+} \mathrm{MSC}$ recovered from the recipient bone marrow and corrected for the genetic abnormality are capable of becoming functional photoreceptors, thus restoring dysfunctional retinas in humans. However, this study represents only the first step in this path, and several questions regarding the ability of the differentiated MSCs to develop fully functional rod and cone receptors remain to be answered.

The ultimate aim of this research is to rescue function in the macula, or more precisely the cone rich foveola, of sufferers of different retinal diseases. In humans, the macula is responsible for $80 \%$ of the vision that enables us to function with ease in society. The treatment of human blinding conditions using this therapeutic approach would then require concentrated functional cell rescue of this small area. Besides the primate, no other animal model (including the rodent) possesses a macular, and thus studying the effects of a relevant functional rescue would be extremely difficult, because most existing biological functional tests for rodents (ERG, behavioral tests) require rescue in a relatively large retinal surface. However, the experiments described in this paper are highly relevant because they establish the following principles: (1) bone marrow pluripotent cells can be differentiated into photoreceptors and genetically modified to correct the underlying disease-causing mutation, and (2) transplanted cells survive without rejection in the retinal space, do not proliferate, express photoreceptor-specific markers, and are capable of attracting synaptic vesicles. Having established these principles, the next step would be to conduct primate experiments focusing on the macula that could then potentially lead to human trials.

\section{References}

Ahmad I, Dooley CM, Afiat S (1998) Involvment of Mash1 in EGFmediated regulation of differentiation in the vertebrate retina. Dev Biol 194:86-98.

Ahmad I, Dooley CM, Thoreson WB, Rogers JA, Afiat S (1999) In vitro analysis of a mammalian retinal progenitor that gives rise to neurons and glia. Brain Res 831:1-10.

Altshuler D, Lo Turco JJ, Rush J, Cepko C (1993) Taurine promotes the differentiation of a vertebrate retinal cell type in vitro. Development 119:1317-1328

Anchan RM, Reh TA, Angello J, Balliet A, Walker M (1991) EGF and TGFalpha stimulate retinal neuroepithelial cell proliferation in vitro. Neuron 6:923-936

Azizi SA, Stokes D, Augelli BJ, DiGirolamo C, Prockop DJ (1998) Engraftment and migration of human bone marrow stromal cells implanted in the brains of albino rats-similarities to astrocyte grafts. Proc Natl Acad Sci USA 95:3908-3913.

Besharse JC, Pfenninger KH (1980) Membrane assembly in retinal photoreceptors I. Freeze-fracture analysis of cytoplasmic vesicles in relationship to disc assembly. J Cell Biol 87:451-463.

Brazelton TR, Rossi FM, Keshet GI, Blau HM (2000) From marrow to brain: expression of neuronal phenotypes in adult mice. Science 290:1775-1779.

Chacko DM, Rogers JA, Turner JE, Ahmad I (2000) Survival and differentiation of cultured retinal progenitors transplanted in the subretinal space of the rat. Biochem Biophys Res Commun 268:842-846.

Davis AA, Matzuk MM, Reh TA (2000) Activin A promotes progenitor differentiation into photoreceptors in rodent retina. Mol Cell Neurosci 15:11-21.

Drukker M, Katz G, Urbach A, Schuldiner M, Markel G, Itskovitz-Eldor J, Reubinoff B, Mandelboim O, Benvenisty N (2002) Characterization of the expression of MHC protein in human embryonic stem cells. Proc Natl Acad Sci USA 99:9864-9869.

Eglitis MA, Mezey E (1997) Hematopoietic cells differentiate into both microglia and macroglia in the brains of adult mice. Proc Natl Acad Sci USA 94:4080-4085.

Ferrari G, Cusella-De Angelis G, Coletta M, Paolucci E, Stornaiuolo A, Cossu G, Mavilio F (1998) Muscle regeneration by bone marrow-derived myogenic progenitors. Science 279:1528-1530.

Gavrieli Y, Sherman Y, Ben-Sasson SA (1992) Identification of programmed cell death in situ via specific labeling of nuclear DNA fragmentation. J Cell Biol 119:493-501.

Huang JC, Ishida M, Hersh P, Sugino IK, Zarbin MA (1998) Preparation and transplantation of photoreceptor sheets. Curr Eye Res 17:573-585.

Jiang Y, Jahagirdar BN, Reinhardt RL, Schwartz RE, Keene CD, OrtizGonzalez XR, Reyes M, Lenvik T, Lund T, Blackstad M, Du J, Aldrich S Lisberg A, Low WC, Largaespada DA, Verfaillie CM (2002) Pluripotency of mesenchymal stem cells derived from adult marrow. Nature 418:41-49.

Kopen GC, Prockop DJ, Phinney DG (1999) Marrow stromal cells migrate 
throughout forebrain and cerebellum, and they differentiate into astrocytes after injection into neonatal mouse brains. Proc Natl Acad Sci USA 96:10711-10716.

Lai CM, Brankov M, Zaknich T, Lai YK, Shen WY, Constable IJ, Rakoczy PE (2001) Inhibition of angiogenesis by adenovirus-mediated sFlt-1 expression in a rat model of corneal neovascularization. Hum Gene Ther 12:1299-1310.

Lillien L, Cepko C (1992) Control of proliferation in the retina: temporal changes in responsiveness to FGF and TGF alpha. Development 115:253-266.

Lolley RN, Rong H, Craft CM (1994) Linkage of photoreceptor degeneration by apoptosis with inherited defect in phototransduction. Invest Ophthalmol Vis Sci 35:358-362.

Mackay AM, Beck SC, Murphy JM, Barry FP, Chichester CO, Pittenger MF (1998) Chondrogenic differentiation of cultured human mesenchymal stem cells from marrow. Tissue Eng 4:415-428.

Mezey E, Chandross KJ, Harta G, Maki RA, McKercher SR (2000) Turning blood into brain: cells bearing neuronal antigens generated in vivo from bone marrow. Science 290:1779-1782.

Muraglia A, Cancedda R, Quarto R (2000) Clonal mesenchymal progenitors from human bone marrow differentiate in vitro according to a hierarchical model. J Cell Sci 113:1161-1166.

Nishida A, Takahashi M, Tanihara H, Nakano I, Takahashi JB, Mizoguchi A, Ide C, Honda Y (2000) Incorporation and differentiation of hippocampus-derived neural stem cells transplanted in injured rat retina. Invest Ophthalmol Vis Sci 41:4268-4274.

Orlic D, Kajstura J, Chimenti S, Jakoniuk I, Anderson SM, Li B, Pickel J, McKay R, Nadal-Ginard B, Bodine DM, Leri A, Anversa P (2001) Bone marrow cells regenerate infarcted myocardium. Nature 410:701-705.

Petersen BE, Bowen WC, Patrene KD, Mars WM, Sullivan AK, Murase N, Boggs SS, Greenberger JS, Goff JP (1999) Bone marrow as a potential source of hepatic oval cells. Science 284:1168-1170.

Phinney DG, Kopen G, Isaacson RL, Prockop DJ (1999) Plastic adherent stromal cells from the bone marrow of commonly used strains of inbred mice: variations in yield, growth, and differentiation. J Cell Biochem 72:570-585.
Pittenger MF, Mackay AM, Beek SC, Jaiswal RK, Douglas R, Mosca JD, Moorman MA, Simonetti DW, Craig S, Marshak DR (1999) Multilineage potential of adult human mesenchymal stem cells. Science 284:143-147.

Pressmar S, Ader M, Richard G, Schachner M, Bartsch U (2001) The fate of heterotopically grafted neural precursor cells in the normal and dystrophic adult mouse retina. Invest Ophthalmol Vis Sci 42:3311-3319.

Shen WY, Rakoczy PE (2001) Uptake dynamics and retinal tolerance of phosphorothioate oligonucleotide and its direct delivery into the site of choroidal neovascularization through subretinal administration in the rat. Antisense Nucleic Acid Drug Dev 11:257-264.

Tomita M, Adachi Y, Yamada H, Takahashi K, Kiuchi K, Oyaizu H, Ikebukuro K, Kaneda H, Matsumura M, Ikehara S (2002) Bone marrowderived stem cells can differentiate into retinal cells in injured rat retina. Stem Cells 20:279-283.

Tropepe V, Coles BL, Chiasson BJ, Horsford DJ, Elia AJ, McInnes RR, van der Kooy D (2000) Retinal stem cells in the adult mammalian eye. Science 287:2032-2036.

Vogel G (2000) Stem cells: new excitement, persistent questions. Science 290:1672-1674.

Wiedenmann B, Franke WW (1985) Identification and localization of synaptophysin, an integral membrane glycoprotein of Mr 38,000 characteristic of presynaptic vesicles. Cell 41:1017-1028.

Woch G, Aramant RB, Seiler MJ, Sagdullaev BT, McCall MA (2001) Retinal transplants restore visually evoked responses in rats with photoreceptor degeneration. Invest Ophthamol Vis Sci 42:1669-1676.

Woodbury D, Schwarz EJ, Prockop DJ, Black IB (2000) Adult rat and human bone marrow stromal cells differentiate into neurons. J Neurosci Res 61:364-370.

Young MJ, Ray J, Whiteley SJ, Klassen H, Gage FH (2000) Neuronal differentiation and morphological integration of hippocampal progenitor cells transplanted to the retina of immature and mature dystrophic rats. Mol Cell Neurosci 16:197-205.

Zhang X, Bok D (1998) Transplantation of retinal pigment epithelial cells and immune response in the subretinal space. Invest Ophthalmol Vis Sci 39:1021-1027. 